\title{
Disciplinarização dos estudos em Análise do Discurso
}

Bethania Mariani (UFF/CNPq/FAPERJ)

Vanise Medeiros (UFF/CNPq/FAPERJ)

Nunca começa onde começa oficialmente. Começa antes.

(Eni Orlandi, 2009)

\section{Palavras iniciais}

Qual o estado atual das pesquisas em Análise de Discurso no Brasil? Essa pergunta, para ser objeto de reflexão, demanda uma outra: à Análise do Discurso corresponde um campo de produção de conhecimento nas Ciências Humanas e Sociais já estabelecido e em transmissão nas instituições universitárias? Sendo a resposta positiva para esta questão, qual a conjuntura teórica que constituiu tanto sua institucionalização quanto sua transmissão?

Uma nota de advertência antes de prosseguirmos: como nos lembra Pêcheux (1983), é necessário desautomatizar a repetição das formas de pensar e, também, a pura repetição de termos ou expressões que, apesar de homônimos, remetem para conceitos muitas vezes distintos. É o que queremos problematizar inicialmente.

Embora de uso bastante frequente nos estudos da linguagem, o termo 'discurso' e as expressões 'análise do discurso', 'análise de discurso', 'produção de conhecimento', 'ciências humanas e sociais', 'institucionalização' e 'transmissão' não possuem sentidos transparentes nem portam evidências em si mesmos. Essas expressões, e mesmo a que é nosso objeto de investigação, a 'análise de discurso', significam dentro de "configurações discursivas" (MILNER, 1989) que marcam distintas maneiras de se conceber ciência, conforme a doutrina epistemológica em jogo. Assim, é importante esclarecer de que lugar falamos quando nos propomos a escrever sobre a Análise de Discurso no momento de publicação dessa Gragoatá 34. E, já de imediato, esclarecemos nossa posição teórica. Situamo-nos em um lugar da teoria do discurso no 
qual se imbrica o pensamento francês e o pensamento brasileiro, e cujo entrelaçamento porta uma memória a ser mencionada, e retomada em vários momentos da escrita desse texto: a Análise do Discurso que se desenvolve na França, com os trabalhos de Michel Pêcheux, durante sua permanência no CNRS a partir dos anos sessenta, à frente de uma equipe multidisciplinar; e os trabalhos de Pêcheux em sua reterritorialização no Brasil, com outros desdobramentos teóricos e analíticos, a partir das pesquisas de Eni Orlandi, em torno do final dos anos setenta, no Instituto de Estudos da Linguagem, na UNICAMP.

Também, de imediato, trazemos para dialogar com o nosso texto dois artigos de Orlandi - (2012a) Apagamento do político na ciência: notas à história da Análise de Discurso. Fragmentação, diluição, indistinção de sentidos e revisionismo; e (2012b) Análise de Discurso e contemporaneidade científica -, e o de Scherer \& Petri (2012) - Le mouvement et les déplacements des études sur le discours à partir des années 1980 et leur disciplinarisation: le cas brésilien.

\section{O ato de saber, a disciplinarização e a historicidade}

Comecemos retomando Auroux (2008), tendo em vista que, para esse autor, na compreensão da produção de saber como conhecimento, há que se distinguir os saberes tácitos, que constituem nossas práticas cotidianas, dos saberes que portam formas de representação seja das línguas, seja das relações humanas, seja do mundo etc. No âmbito da produção de saber como conhecimento, Auroux define o ato de saber como sendo limitado e possuindo, por definição, uma temporalidade que não é sem horizonte de retrospecção e sem horizonte de projeção. Afirma Auroux: "o saber não destrói seu passado, mas sim, o organiza, o escolhe, o esquece, o imagina ou o idealiza e também tenta antecipar seu futuro, sonhando enquanto o constrói." (AUROUX, 2008, PG). A história presente de uma disciplina inclui, desse modo, sua historicidade, ou seja, a memória da conjuntura teórica que a constitui; o processo de sua disciplinarização enquanto produção de saber, isto é, os mecanismos político-acadêmicos que a institucionalizam, permitindo sua transmissão; e, por fim, a possibilidade de apreensão das tênues linhas que projetam seu porvir.

Disciplina e disciplinarização são dois termos que também precisam ser definidos. Puech e Chiss (1999), linguistas que se ocupam da História das Teorias Linguísticas, propõem a utilização do termo 'disciplina' para assinalar que a produção de conhecimento necessita de ser transmitida, e que as fronteiras dessa produção não são totalmente definidas ou delimitadas, uma vez que são configuradas discursivamente, constituídas por processos que não são estanques. Com a noção de disciplina, os autores colocam a questão da transmissão como central: uma teoria de linguagem supõe textos fundadores e seus comentadores. 
Com o termo 'disciplinarização', pretendemos levar em consideração não apenas o aspecto conceitual, mas também os aspectos práticos que organizam a transmissão: inscrição nas instituições científicas, utilização e uso dos saberes às vezes de forma vulgarizada na escola, nos colégios, nas universidades. (CHISS; PUECH, 2010, p. 72)

Um aspecto ligado à disciplinarização é o que os autores chamam de incremento da expansão da escolarização, sobretudo em sua relação com as condições históricas em que são ordenadas políticas para as línguas e para a educação de um modo geral. A compreensão das condições históricas que propiciam a emergência de uma disciplina é crucial para se desfazerem as evidências que deixam a transmissão da produção de conhecimento como discursos sem sujeito. Chiss e Puech (1999) enfatizam que os discursos sobre o objeto e sobre o método são discursos afetados pelos discursos disciplinares, os quais organizam a forma e as estratégias de transmissão da teoria. "Em suma, a disciplina é menos um estado de fato que um processo sempre já começado e recomeçado". (CHISS; PUECH, 1999, p. 10).

As condições de transmissão de um saber bem como a transmissão em si se encontram sempre perpassadas pelos atos de enunciação daqueles que se ocupam desse processo de disciplinarização, o que não quer dizer, ingenuamente, que haveria um estado de ciência pura, isenta, ou não afetada pelos processos de transmissão. Por outro lado, os que se ocupam da disciplinarização e da transmissão nem sempre (com)partilham o lugar teórico do conhecimento em jogo, o que afeta, igualmente, a transmissão. Em outras palavras, não há como se desembaraçar da carga imaginária que se produz sobre o que está sendo disciplinarizado e transmitido: as imagens têm força inegável e constituem a própria transmissão. E, também, como nos lembram Chiss e Puech:

Formuler l'hypothèse d'une reconnaissance toujours possible du discours disciplinaire derrière le discours sur l'objet et sur la méthode, c'est supposer au contraire que des conditions d'énonciation spécifique ordonnent toujours les savoirs savants en apparence les plus désincarnés. C'est également envisager des strates du discours disciplinaire où les images de la discipline se combinent, se superposent, se font écho en foction de stratégies variées, depois l'invention des connaissances jusqu'à leur socialisation la plus large. (CHISS; PUECH, 1999, p. 18 , tradução nossa)
Formular a hipótese de um reconhecimento sempre possível do discurso disciplinar por trás do discurso sobre o objeto e sobre o método é supor, ao contrário, que condições de enunciação específicas sempre organizam os saberes da ciência aparentemente menos afetados pela realidade. É igualmente considerar estratos do discurso disciplinar em que as imagens da disciplina se combinam, se superpõem, fazem eco em função de estratégias várias, desde a invenção dos conhecimentos até sua socialização mais larga ${ }^{1}$. (CHISS; PUECH, 1999, p. 18)

O conhecimento é produzido, é disciplinarizado e circula em condições histórico-enunciativas de produção bastante específicas, o que significa sua inserção em políticas científicas e acadêmicas nacionais e, ainda que indiretamente, internacionais também. 'Política científica' é uma expressão que remete para um tensionamento entre o controle e a independência da pesquisa e do pesquisador. O funcionamento das políticas científicas implica um gerenciamento que perpassa a produção de conhecimento 
tanto no âmbito institucional, em termos do incremento de um campo disciplinar, como individual, do pesquisador (com ou sem seu grupo) na elaboração de seu projeto, com justificativas para a escolha do objeto de estudo, explicações sobre a relevância social ou para a formação de jovens pesquisadores ou, ainda, para o próprio campo teórico-metodológico, além de limitações geradas por formas de financiamento, o que representa formas de estabelecimento de vínculos com órgãos de fomento e seus instrumentos de avaliação (GUIMARÃES, 2003).

Produzir conhecimento, nesse sentido, é se encontrar submetido aos efeitos da historicidade - seja aderindo, seja resistindo, seja propondo criticamente alternativas à política vigente -, que constituem e delimitam o lugar da produção científica no estabelecimento de relações com políticas de Estado, com a sociedade e com a universidade, enquanto lugar privilegiado da disciplinarização e transmissão. Além disso, nos dias atuais, ainda no que tange à produção de conhecimento de um modo geral, a velocidade da internet é um outro aspecto que precisa ser considerado como parte dos efeitos de historicidade, pois, ao ser incorporada ao trabalho científico, a internet vem produzindo uma diluição nas formas do pensar teórico, e a pesquisa, muitas vezes, fica reduzida a sites de busca de 'informações', com textos obscuros e pouco confiáveis. Tudo isso nos leva a refletir sobre o lugar dessa produção científica que, situada no escopo dos estudos da linguagem, recebeu o nome de Análise do Discurso, conforme o título que Pêcheux deu ao seu livro Analyse Authomatique du Discours (1969), conhecido como AAD69.

\section{Análise de discurso: memórias e atualidades}

No Brasil, os estudos em Análise de Discurso surgem por volta dos anos 70 do século XX. São estudos que se originam na Europa, especialmente na França, na década anterior, e têm como base a obra do filósofo Michel Pêcheux, uma obra profundamente afetada pelas releituras de três fundadores de discursividades: Marx, Freud e Saussure. Henry, em artigo que busca explicar a conjuntura intelectual francesa que está na base das condições de produção do AAD69, afirma que

Pêcheux queria se apoiar sobre o que lhe parecia já ter estimulado uma reviravolta na problemática dominante das ciências sociais: o materialismo histórico tal como Louis Althusser o havia renovado a partir de sua releitura de Marx; a psicanálise, tal como a reformulou Jacques Lacan, através de seu 'retorno a Freud', bem como certos aspectos do grande movimento chamado, não sem ambiguidades, de estruturalismo. (HENRY, 1990, p. 14)

Por outro lado, Mazière (2008) e Maingueneau (1990) localizam os inícios da Análise do Discurso enfatizando ângulos dessa 
historicidade de modos distintos. Mazière realça a interlocução crítica com o artigo Discourse analysis, de Z. Harris (1952), e discussões situadas por Jean Dubois e seu grupo (MAZIÈRE, 2008). Maingueneau, para distinguir a escola americana da francesa, afirma que a Análise do Discurso, na França, inscreve-se na tradição das pesquisas filológicas e filosóficas com o texto, enquanto que a tradição americana filia-se à etnometodologia, sendo, nessa perspectiva, mais voltada para a oralidade (MAINGUENEAU, 1990). Para ambos, o que se convencionou chamar de Escola Francesa de Análise do Discurso, em torno de Michel Pêcheux e seu grupo, apresenta um diferencial que é o de propor como horizonte uma análise discursiva de textos distinta de uma hermenêutica e distinta, sobretudo, da análise de conteúdo. Para compreensão dos desdobramentos dos estudos discursivos do grupo Pêcheux, é necessário fazer uma tomada de posição em que a história e a ideologia são constitutivas da materialidade linguística, e que o sujeito é dividido pelo inconsciente e interpelado pela ideologia.

$\mathrm{Na}$ conjuntura francesa dos anos 60, assinando como Thomas Herbert, Pêcheux chama a atenção para uma rarefação do pensamento crítico no âmbito das ciências humanas uma vez que as teorias desse campo do conhecimento, imersas em dicotomias e oposições, reproduzem efeitos das formas filosóficas do século XIX, sobretudo as de base kantiana. Essas oposições são estabelecidas a partir "do surgimento do indivíduo como sujeito histórico novo e a racionalização da sociedade (...)" (HERBERT-PÊCHEUX, 2011 [1969b], p. 187). Tal atravessamento das ciências humanas por essas formas de pensar produz, no caso específico dos estudos linguísticos, uma dicotomização teórica que opõe a liberdade do falante, sua possibilidade de criar, ao sistema da língua, que restringe essas mesmas possibilidades de criação. E nessa mesma chave, com uma reflexão que acompanha sua obra, Pêcheux recorta também a oposição entre estudos empiristas e estudos formalistas. Esse mapeamento das dicotomias desemboca na depreensão de três tendências dos estudos linguísticos, segundo Pêcheux: a tendência formalista-logicista, a tendência histórica e a linguística da fala (PÊCHEUX, 1988 [1975]). À Análise de Discurso não caberia uma quarta tendência, mas sim o trabalho de construção de um domínio teórico situado na contradição aberta pelas três outras tendências. Um lugar teórico de onde se pudesse fazer intervenções críticas com abertura para campos de questões situadas fora das três tendências mencionadas, ou seja, questões relacionadas às noções de sujeito, sentido, inconsciente e ideologia. Para Pêcheux, a resposta à pergunta se haveria "uma via para a linguística fora do logicismo e do formalismo?" (PÊCHEUX, 1981 [1998]) constitui uma forma de circunscrever os efeitos do idealismo subjetivista e, ao mesmo tempo, a abertura de um outro campo de questões para os estudos da linguagem, sobretudo para estudos da produção de sentidos que incluíssem o real da língua, 
o real da história, e a noção de sujeito dividido pelo inconsciente e interpelado pela ideologia como categorias teóricas.

Nesse quadro de reflexões, que se desdobra entre os anos 60 e 80, a Análise do Discurso, a partir de Pêcheux, é teorizada de forma a reinvestigar sempre seus fundamentos de partida. Situa-se, dessa forma, como uma disciplina de entremeio, disciplina que abre seu campo de questões para uma semântica de base materialista, a qual não separa discurso e prática política.

Scherer e Petri (2012) referem-se ao acontecimento da entrada dos estudos do discurso no Brasil como um momento inicial da disciplinarização dessa tomada de posição teórica sobre uma forma específica de produzir conhecimento sobre a linguagem: o discursivo. Esse marco é relevante para que se compreendam os desdobramentos teóricos e os destinos acadêmicos que os estudos do discurso tomam ao serem disciplinarizados, inicialmente, nos cursos de Pós-graduação brasileiros e, pelo menos duas décadas mais tarde, nos cursos de graduação.

Na década de 70 e na de 80 do século XX, os estudos discursivos no Brasil também vão de encontro ao terreno conflagrado das três tendências delineadas por Pêcheux. A posição teórica que traz como objeto o discurso entra em descontinuidade com os estudos linguísticos até então vigentes, ou seja, instala-se como acontecimento teórico, como ponto de ruptura com a linguística que até então se fazia: não se trata mais de um quadro teórico-metodológico formalista ou empirista para conceituar e analisar sistemas linguísticos, mas sim de uma mudança radical de terreno, que implica um objeto próprio - o discurso, definido como efeito de sentidos entre locutores -, e inclui, em seu enquadre teórico, o materialismo e a psicanálise articulados aos estudos da linguagem. É uma posição teórica que traz um engajamento político próprio: falar é tomar posição no sócio-histórico, é inscrever-se subjetivamente em redes de sentidos com a ilusão de se estar na origem e no controle do dizer.

Dos anos 90 para o momento atual houve um crescimento expressivo de estudos discursivos, porém, com enquadres teórico-metodológicos bastante diferenciados das reflexões de Pêcheux. Garantidas por uma crescente disciplinarização no âmbito universitário de pós-graduação, a palavra 'discurso' e as expressões 'análise do/de discurso' e 'teorias do discurso' circulam cada vez mais fortemente no campo dos estudos da linguagem, no Brasil, em quase 40 anos, sustentando, a cada vez que são empregadas, referenciais teóricos e métodos de análise bem distintos. As distinções, no entanto, muitas vezes vão se diluindo, mesmo tendo-se em vista conceitos de base como sujeito, sentido, inconsciente, ideologia, além da forma de organização dos corpora e os objetivos propostos para analisá-los. De que forma se realiza a disciplinarização das teorizações? Verificar em detalhes a especificidade do modo como se vem realizando a transmissão desses

Niterói, n. 34, p. 15-25, 1. sem. 2013 
distintos campos de produção de conhecimento que se reúnem sob o nome 'análise do discurso', cada qual em sua singularidade, é tarefa ainda a ser desenvolvida por um grupo de pesquisadores de forma a acompanhar, em parte, seus efeitos em dissertações, teses, publicações e apresentações em congressos.

A comunidade imaginada 'somos todos do discurso' institui, de um lado, uma forte homogeneidade que tem sua relevância quando se trata de política científica, mas, por outro lado, pode apagar as filiações teóricas em suas bases de sustentação epistemológicas. Se o termo 'discurso' e a expressão 'análise do discurso' ganham em visibilidade e circulação, eventualmente perdem na espessura teórica que garante as diferenças, ou seja, no modo como articulam os processos de produção de sentidos com o histórico-ideológico, de um lado, e com a noção de sujeito, de outro. A palavra 'discurso', enquanto conceito teórico, por exemplo, está definida em Benveniste, em Pêcheux, em Lacan, em Foucault, em Maingueneau, em Charaudeau, em Fairclough; mas, muitas vezes, não se encontra definido conceitualmente em outros autores, embora seja usada como referência genérica à fala.

Assim, o que se observa é que 'discurso' e 'análise do/de discurso' são expressões que garantem o pertencimento à comunidade imaginada de analistas do/de discurso, mas como estão associadas muitas vezes de maneira generalizante ou misturada a intelectuais com filiações teóricas e interesses distintos acabam por embaralhar as perspectivas, retirando a densidade das teorias e das análises específicas. Em outras palavras, com essa forte circulação, não se garante no transmissível a necessária reflexão crítica sobre as fronteiras epistemológicas que constituem tão diferentes domínios e análises de linguagem aí propostos. Mesmo assim, é possível perguntar: mencionar nomes próprios de autores, de teorias, e citar conceitos, seria uma prerrogativa suficiente para fundamentar os saberes de um campo de produção de conhecimento e trabalho em toda sua complexidade interna e demarcação de fronteiras?

Sem dúvida, como nos adverte Orlandi (2012)

temos a Análise de Discurso, a Pragmática, a Teoria da Enunciação, a Análise Textual e muitas disciplinas que tratam da relação com a exterioridade, junto a disciplinas mais antigas, como a Semiótica, a Retórica, a Semiologia, a Filosofia da Linguagem. (ORLANDI, 2012a, p. 26, grifos nossos).

Porém, e esse é um dos aspectos para os quais Orlandi chama a atenção, esse tratamento da relação entre a linguagem e a exterioridade não se processa da mesma forma. Conforme a autora, discutindo a relação entre disciplinas e o apagamento dos muitos sentidos da palavra 'discurso',

Passa-se a indistinguir as divisões disciplinares em suas diferentes posições teóricas (face a noções como discurso, exte- 
rioridade, contexto, sujeito etc.). Reúne-se assim no mesmo lugar teórico - como se isso fosse possível - a filosofia da diferença (Foucault, Derrida, Deleuze etc.), a semiologia, a semiótica, a filologia etc. (ORLANDI, 2012, p. 29)

Trazemos um exemplo. Ideologia e inconsciente são conceitos que, quando aplicados ou transferidos sem uma justificativa teórica de sua entrada em um quadro teórico-metodológico, além de ficarem esvaziados de seu potencial crítico, podem produzir contradições internas na análise pretendida. Não basta mencionar o inconsciente como um atributo do sujeito se não se tem como memória a obra de Freud bem como a consequente discussão que fundamenta criticamente a desnaturalização de concepções formadas durante o século XVIII, constituindo o homem como objeto de análise e, por conseguinte, o campo das ciências humanas tal como o conhecemos hoje.

\section{Uma especificidade da disciplinarização}

Trazemos para reflexão um acontecimento histórico bastante significativo dessa virada do início dos anos 90, um acontecimento que impulsionou e consolidou, a nosso ver, a disciplinarização da Análise de Discurso. Na primeira reunião da Associação Nacional de Pós-Graduação em Letras e Linguística (ANPOLL), em 1986, em Curitiba, ocorreu a criação de vários Grupos de Trabalho, dentre eles a do Grupo de Trabalho em Análise do Discurso. Fundava-se O GT, com o aval da política científica da época, e a partir de um exercício efetivamente realizado de investimento teórico, de tradução de textos, de orientação de alunos, de aulas ministradas, de financiamentos de pesquisas e de participações em congressos um forte núcleo de pesquisadores do discurso associados entre si, e, ao mesmo tempo, sustentando eticamente suas diferenças. Foi uma vitória política, portanto, o reconhecimento do percurso de trabalho e pesquisas realizadas, o que promoveu o fortalecimento da disciplinarização e transmissão dos estudos do discurso. Foi a pesquisadora Eni Orlandi, professora do Instituto de Estudos da Linguagem, UNICAMP, quem fundou o GT de AD e coordenou seu primeiro encontro durante as atividades do II Congresso da ANPOLL, no Rio de Janeiro, em 1987.

Desde sua fundação, o GT de AD abrigou diversas tendências teóricas, organizando os pesquisadores em uma comunidade. Tomo o termo 'comunidade' na forma como Auroux (2008) o conceitua, tanto em seu sentido mais genérico - o pertencimento a grupos se dá antes mesmo do pertencimento ao Estado -, quanto em seu sentido estrito do comunitarismo científico de grupos que sustentam alianças ou concorrem entre si conforme as políticas em jogo e, portanto, sempre inseridos em condições de produção determinadas. No ato de fundação do GT, como bem nos lembra Indursky, ex-coordenadora do GT e ex-presidente da ANPOLL: 
No que tange ao GT de Análise do Discurso (GETAD), desde logo ele abrigou em seu interior diferentes perspectivas teóricas - Escola Francesa de Análise do Discurso, Semiótica Discursiva, Teoria da Enunciação, Teoria do Texto que se interessam pelo discurso, apresentando, assim, uma pluralidade de pesquisas, em lugar de priorizar uma única vertente. Esse modo de funcionamento faculta o desenvolvimento concomitante de várias pesquisas, sem haver imposição de um trabalho único e uniforme para todos seus membros. Essa política interna permite a administração democrática desse espaço institucional, sem que a usual disputa de poder/prestígio interfira no ritmo dos trabalhos. (INDURSKY, 1994)

A fundação do GT no âmbito da ANPOLL, em 1986, torna visível um processo histórico de disciplinarização da Análise do Discurso que já estava ocorrendo desde o início da década de 80 do século passado: do Instituto de Estudos da Linguagem, UNICAMP, para outros cursos de Letras no Brasil, em um movimento que partiu dos programas de pós-graduação para o ensino de graduação.

Muitas vezes sob o nome Análise do Discurso, disciplina-se universitariamente uma comunidade imaginária, como dissemos anteriormente, encobrindo diferenças teóricas que, se trabalhadas, poderiam se revelar bastante produtivas em suas especificidades, a começar pelas noções de língua, sujeito, sentido e seguindo para outras, como texto (verbal ou não-verbal), enunciação e interlocução.

De qualquer maneira, qualquer que seja a discussão sobre Análise de Discurso, esta não se dará sem Eni P. Orlandi e Michel Pêcheux, autores que demonstraram a relevância da construção de um lugar teórico e de um método próprio para a construção de dispositivo de análise sobre o funcionamento da linguagem em sua relação constitutiva com o histórico-ideológico. A Análise de Discurso é uma disciplina de entremeio que está sempre retornando e reinvestigando seus fundamentos ao mesmo tempo em que sua reflexão desloca e reterritorializa conceitos vinculados aos campos teóricos com os quais dialoga: a linguística, mais especificamente a teoria da enunciação tomada de um ponto de vista não subjetivo; o materialismo histórico, enquanto teoria das formações sociais e suas transformações; e, também, a psicanálise, base para se compreender o sujeito dividido, uma vez que o homem não é senhor de sua morada, como afirma Freud.

O trabalho da análise discursiva dos processos de produção dos sentidos, e de seus efeitos, quando tomado do ponto de vista de Pêcheux e Orlandi, incide na suspensão das certezas, na crítica das evidências, na desconstrução das verdades, na escuta do silêncio e das políticas de silenciamento. O político, compreendido aqui como a divisão de sentidos na língua, é dessa forma constitutivo do trabalho de análise. 
E a resistência, tema principal desse número da Gragoatá 34, faz parte do movimento da divisão dos sentidos e do sujeito.

\section{REFERÊNCIAS}

AUROUX, S. A historicidade das ciências. In: AUROUX, S. A questão da origem das linguas seguido de A historicidade das ciências. Tradução de Mariângela Joanilho. Campinas: Editora RG, 2008. CHISS, Jean-Louis; PUECH, Christian. Entrevista. In: Linguagem, Teoria, História. Série Cogitare, no 11, PPGL, UFSM, 2010.

. Le langage et ses disciplines XIX - -XXe siécles. Paris, Bruxelles: Éditions Duculot, 1999.

FOUCAULT, M. O homem e seus duplos. In: FOUCAULT, M. As palavras e as coisas; uma arqueologia das ciências humanas. Portugália Editora, Barcelos, 1968. p. 395-445.

GUIMARÃES, Eduardo. Política científica e produção de conhecimento no Brasil (uma aliança tecnológica?). In: GUIMARÃES, E. (Org.). Produção e circulação do conhecimento. Política, ciência, divulgação. Campinas, Pontes \& CNPQ/PRONEX \& NJC, 2003. p. 193-207.

HENRY, P. Os fundamentos teóricos da 'Análise Automática do Discurso', de Michel Pêcheux (1969). In: GADET, F. E HAK, T. Por uma Análise automática do discurso: uma introdução à obra de Michel Pêcheux. Campinas, Editora da UNICAMP, 1990, p. 13-37. INDURSKY, F. GT de Análise do Discurso: sete anos de atividades. Revista da Anpoll: o primeiro de muitos números, v. 1, no 1, 1994. p. 37-42. Disponível em: <www.anpoll.org.br/revista/index.php/ revista/issue/view/14/showtoc.>

MAINGUENEAU, D. Novas tendências em análise do discurso. Campinas, Pontes, 1990.

MAZIÈRE, Francine. Análise do discurso, história e práticas. São Paulo, Parábola, 2008.

MILNER, Jean-Claude. Introduction à une science du langage. Paris: Seuil, 1989.

ORLANDI, Eni P. Ler Michel Pêcheux hoje. In: ORLANDI, Eni (Org.). Análise de discurso. Michel Pêcheux. Textos escolhidos por Eni Puccinelli Orlandi. Campinas, Pontes, 2011, p. 11-20.

Apagamento do político na ciência: notas à história da análise de discurso-fragmentação, diluição, indistinção de sentidos e revisionismo. In: . Discurso em Análise: sujeito, sentido, ideologia. Campinas, SP: Pontes, 2012a. p. 13-36.

. Análise de Discurso e contemporaneidade científica. In: . Discurso em Análise: sujeito, sentido, ideologia. Campinas, SP: Pontes, 2012b. p. 37-54. 
PÊCHEUX, Michel. As ciências humanas e o momento atual. In: ORLANDI, Eni (Org.) Análise de discurso. Michel Pêcheux. Textos escolhidos por Eni Puccinelli Orlandi. Campinas, Pontes, [1969b] 2011, p. 175-201. [1981] 1998.

O discurso: estrutura ou acontecimento. Campinas, Pontes, - Semântica e discurso: uma crítica à afirmação do óbvio. Campinas, SP: Editora da Unicamp, [1975] 1988.

SCHERER, Amanda E.; PETRI, Verli. Discours ou discourse: invention, configuration, transmission et disciplinarisation au Brésil. In: Letras, Santa Maria, UFSM, vol. 18, n. 2, p. 9-18, jul./dez., 2008. SÉRIOT, Patrik. Pourquoi Bakhtine n'est pas Pêcheux: un grand malentendu sur l'analyse de discours. In: BRANCO, L. K. A. Castello; RODRIGUES, E. Alves; SANTOS, G. Leopoldino dos (Orgs.). Análise de discurso no Brasil. Pensando o impensado sempre. Uma homenagem a Eni Orlandi. Campinas, RG Editora, 2011. p. 221-230. 